\title{
Variation of stream power with seepage in sand-bed channels
}

\author{
Gopu Sreenivasulu', Bimlesh Kumar ${ }^{2 *}$ and Achanta Ramakrishna Rao ${ }^{3}$ \\ ${ }^{1}$ Department of Civil Engineering, RGM College of Engineering and Technology, Nandyal - 518501, Andhra Pradesh \\ ${ }^{2}$ Department of Civil Engineering, Indian Institute of Technology, Guwahati-781039, India \\ ${ }^{3}$ Department of Civil Engineering, Indian Institute of Science, Bangalore- 560012, India
}

\begin{abstract}
Downward seepage (suction) increases the mobility of the channel. In this study, experimental investigations were carried out to analyse the suction effect on stream power along the downstream side of the flume. It was observed that stream power has a major influence on the stability and mobility of the bed particles, due to suction. Stream power is found to be greater at the upstream side and lower at the downstream side. This reduces the increment in the mobility of the sand particles due to suction at the downstream side. Thus, there is more erosion at the upstream side than the downstream side. It was also found that the amount of deposition of sand particles at the downstream side, because of the high stream power at the upstream side, is greater than the amount of erosion of sand particles from the downstream side.
\end{abstract}

Keywords: friction slope, seepage, sediment transport, stream power, suction

\section{Introduction}

A study of the effect of seepage flows on the detachment of particles from the bed and on further movement of the bed load is of great interest, since this problem is related to the solution of important practical engineering problems. For instance, groundwater movement plays an exceptionally important role when constructing hydraulic structures, particularly dams; these concepts are important when solving problems of the stability of dams and channel slopes. Seepage through boundaries is common due to porosity of the granular material as well as due to level differences between groundwater and surface water in the channel. The presence of seepage from a channel (termed suction), or into it (termed injection), leads to a change in bed deformation conditions and consequently in the hydrodynamic channel characteristics (Dobroklonskii et al., 1976). Due to injection the channel receives more water, whereas due to suction its discharge is reduced. The issues relating to whether seepage reduces or enhances sand-bed stability are still matters of considerable debate (Lu et al., 2008). However, Willets and Drossos (1975), Maclean (1991), Rao and Sitaram (1999) and Rao and Sreenivasulu (2009) suggest that suction increases bed material transport, whereas injection reduces sediment transport and increases particle stability, or does not aid in initiating their movement. Oldenziel and Brink (1974) and Maclean (1991) found experimentally that the streamwise velocity decreases in the upper portion and increases near the bed due to downward seepage or suction. Ali et al. (2003) and Cheng and Chiew (1999) studied the effect of downward seepage on the velocity profile and found that there is an increase in the near-bed velocities due to downward seepage. However, as suction increases the bed material transport, it is felt that there is a need to assess the spatial behaviour of the downward

\footnotetext{
* To whom all correspondence should be addressed.

前 +91 361 2582420; fax: +91 361 2582440; e-mail: bimk@iitg.ernet.in

Received 27 December 2009; accepted in revised form 24 November 2010.
}

seepage along the length of the channel, as this would be more beneficial for field engineers. Whether that position is defined in topologic, geometric or flow-regulated terms, the most striking element of fluvial change occurs in the downstream direction (Knighton, 1987; 1999).

Stream power has a significant influence on many form and process attributes of the fluvial system (Fonstad, 2003). Bagnold $(1963$; 1966) expressed the basic relations between work, energy expenditure of a stream and quantity of sediment transported by the stream, in terms of stream power, as the supply energy for the sediment's motion in a water stream. Phillips (1989) found that the stream power provides a physically-based measure of sediment transport capacity. Lawler (1995) found this quantity useful in describing particle entrainment. Magilligan (1992) and Lecce (1997) found that spatial patterns of stream power influenced the processes and extents of fluvial erosion, transport, and sediment deposition. Abernethy and Rutherford (1998) used stream power indices to describe patterns of bank instability. Baker and Costa (1987) and Wohl (2000) used stream power as a measure of channel mobility thresholds.

Stream power has a relationship with the transport of sediments in fluvial bed channels (Martin and Church, 2000; Petit et al., 2005; Lima, 2007). The spatial patterns of stream power may be used to assess the spatial distribution of stream energy during suction.

Therefore, the purpose of this paper is to determine or assess spatial variation of stream power when downward seepage is taking placed in the sand-bed channel.

\section{Methods}

One approach to studying the problem of alluvial channel stability is by means of a set of laboratory experiments. In order to quantify the seepage effect on stream power and downward variation of stream power, experiments were conducted in a rectangular smooth-walled sand bed tilting flume. The dimensions of the flume were: $25 \mathrm{~m}$ length, $1.8 \mathrm{~m}$ width and $1 \mathrm{~m}$ depth. A schematic view of the tilting flume is shown in 


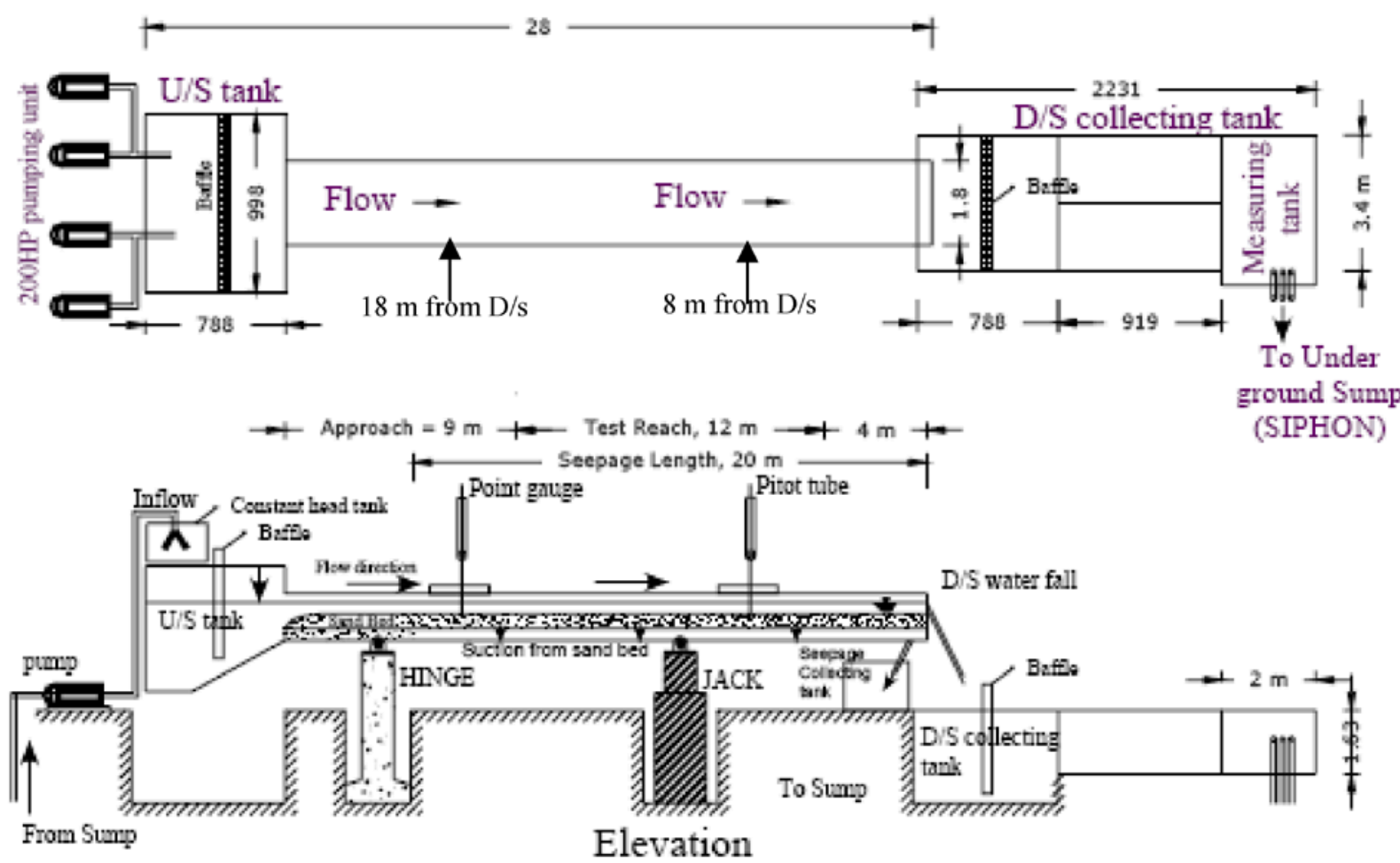

Figure 1

Schematic diagram of experimental setup

Fig. 1. The seepage length of $20 \mathrm{~m}$ was facilitated from the downstream end towards the upstream end. The upstream tank was $3 \mathrm{~m}$ long, $3.8 \mathrm{~m}$ wide and $3.7 \mathrm{~m}$ deep and served to straighten the flow prior to its introduction into the flume. The downstream collection tank was $3.4 \mathrm{~m}$ long, $2 \mathrm{~m}$ wide and $1.63 \mathrm{~m}$ deep. In a re-circulatory mode, the downstream tank served as storage as well as a measuring tank for the water flowing through the flume. A uniform sand bed $(0.3 \mathrm{~m})$ of particle size $0.56 \mathrm{~mm}$ was laid on a perforated sheet at an elevated level from the channel bottom and covered with a fine wire mesh (to prevent the sand falling through) to facilitate the seepage flow through the sand bed. The gradation coefficient was 1.08 , therefore the sand can be assumed to have been composed of fairly uniform material. The space between the perforated sheet and the channel bottom acted as a pressure chamber to allow seepage flow through the sand bed, either in a downward or an upward direction, by creating a pressure difference which was either lower or higher, respectively, than the channel flow. A valve located at the downstream end of the chamber was used to apply the controlled amounts of seepage as suction. After applying seepage to the channel bed, the downstream discharge was measured volumetrically with the help of an interval timer; the difference in the discharge (upstream discharge and downstream discharge) is the seepage discharge. A magnetic flow meter was also installed to cross-check the seepage discharge. Experimental ranges of the measurements taken are given in Table 1.

Initially, the sand bed was made level for all of the experiments with a required bed slope, $S_{0}$. Two different bed slopes ( 0 and 0.00133 ) were used. Then inflow discharge, $Q$, is allowed. This run was continued for several hours (4 to $8 \mathrm{~h}$ ) so that the channel geometry and the longitudinal slope adjusted to the point where there is no visible sediment movement in the

\begin{tabular}{|c|c|c|c|c|}
\hline \multicolumn{5}{|c|}{ Table 1 } \\
\hline$Q\left(\mathbf{m}^{3} / \mathbf{s}\right)$ & $q\left(\mathbf{m}^{3} / \mathbf{s}\right)$ & $\begin{array}{c}\text { Average } \\
y(\mathbf{m})\end{array}$ & $S_{0}$ & $\begin{array}{c}\text { Average } \\
S_{w}\end{array}$ \\
\hline 0.042 & 0 & 0.1126 & 0 & 0.000209 \\
\hline 0.042 & 0.0084 & 0.107 & 0 & 0.0002 \\
\hline 0.042 & 0.0168 & 0.1 & 0 & 0.000197 \\
\hline 0.042 & 0.0252 & 0.092 & 0 & 0.000199 \\
\hline 0.042 & 0.336 & 0.082 & 0 & 0.000211 \\
\hline 0.029 & 0 & 0.066 & 0.00133 & 0.00012 \\
\hline 0.029 & 0.0058 & 0.051 & 0.00133 & 0.000115 \\
\hline 0.029 & 0.116 & 0.041 & 0.00133 & 0.000113 \\
\hline 0.029 & 0.174 & 0.035 & 0.00133 & 0.000115 \\
\hline 0.029 & 0.232 & 0.032 & 0.00133 & 0.00121 \\
\hline
\end{tabular}

channel. After reaching this stable condition, seepage flow, $q$ (suction), was slowly allowed. Before and after the application of seepage, the water surface slope was obtained by using a Pitot tube and micro-manometer. The Pitot tube was attached to a trolley; by moving the trolley, the static pressure was measured at different locations by connecting the static pressure slot to the capacitance micro-manometer (Rao, 2005), with an accuracy of $\pm 0.015 \mathrm{~mm}$ of water head. Measurements were taken at regular intervals along the channel by using a digital micro-manometer, in order to determine the water surface slope, $S_{w}$. Flow depths along the central line of the channel were measured at regular intervals using a point gauge and the average depth $y$ was obtained. The amount of $Q$ was measured volumetrically and $q$ (seepage flow) was measured with calibrated magnetic flow meter. The amount of seepage flow was varied from $20 \%$ to $80 \%$ of the total inflow discharge. 
Thus, the basic variables, $S, Q, q, S_{w}$ and $y$, were obtained in every experimental run. A tailgate at the downstream end of the channel was used to adjust and maintain the flow depth. Pressure tapings were provided at some sections inside the sand bed to measure the seepage gradients and verify the uniformity of seepage flow.

\section{Results and discussion}

A stable relationship between sediment transport and flow can, at best, only be expected in a situation where the mechanisms controlling sediment transport are dependent only on the rate of flow of water in the channel and on seepage occurring through the channel. Thus, it is felt that the 'stream power concept' is more appropriate for describing seepage-induced incipient motion in an alluvial channel. Stream power is the energy available to transport sediment (Velikanov, 1954; Bagnold, 1966). Given basic knowledge of a stream cross section, it is possible to compute the stream power per unit boundary area for a range of flows. In functional form, stream power of the channel per unit width and unit length of the channel can be expressed as follows (Petit et al., 2005):

$$
\text { Stream Power }=\Omega=\frac{\gamma Q h_{f}}{B L}=\tau_{b} u
$$

where:

$\gamma=$ unit weight of water

$Q=$ discharge in the channel

$h_{f}$ is the energy loss over a given reach of the channel

$B$ is the channel width

$L$ is the channel length

$\tau_{b}$ is calculated as $\gamma R_{b} S_{f}$, where $R_{b}$ is the hydraulic radius of the bed and $S_{f}$ is the friction slope. The stream power can be expressed in dimensionless form by dividing $\tau_{b} u$ with $\left(\gamma_{s}-\gamma\right) v$, where $\gamma_{s}$ the specific weight of sediments and $v$ is the kinematic viscosity of the water and is expressed as:

$$
\Omega \mathrm{s}=\frac{\tau_{b} u}{\left(\gamma_{s}-\gamma\right) v}
$$

The gradually varied flow equation (Chow, 1959), with energy/ momentum correction factor as unity, is used in computing the $S_{f}$ as follows:

$$
S_{f}=S_{o} F^{2}+S_{w}\left(1-F^{2}\right)
$$

where:

$$
F=\text { Froude number }=u / \sqrt{g y} .
$$

Thus by knowing $S_{f}$, the bed shear stress, $\tau_{b}$ is computed by the following relation:

$$
\tau_{b}=\gamma R_{b} S_{f}
$$

$R_{b}$ value can be computed by using Vanoni and Brooks (1957) wall correction formula. Pitot tube has been used for measurement of velocity using a digital micro manometer. As $S_{o}$ is fixed in an experiment, stream power is greatly influenced by the parameters $S_{w}$ and $y$. Thus it is interesting to analyse the behaviour of these 2 parameters when uniform suction is taking place in the channel. Figure 2 shows the water surface slope variation over the channel length for different suction rates.

As shown in Fig. 2, when the suction takes place and its quantity gets increased, it is found that the water surface

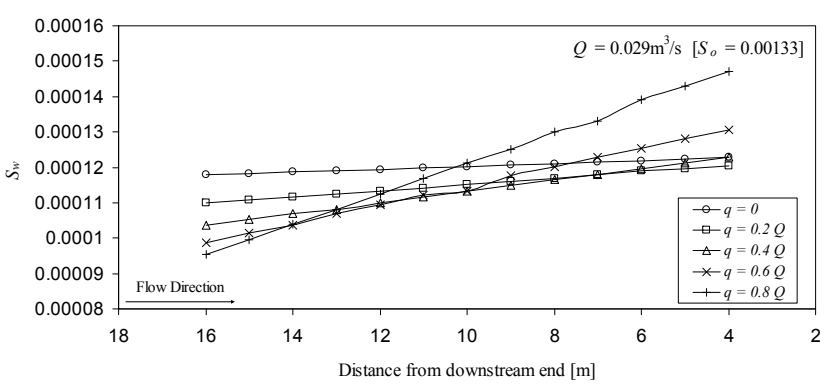

Figure 2a

Downstream behaviour of water surface slopes $\left(S_{o}=0.00133\right)$

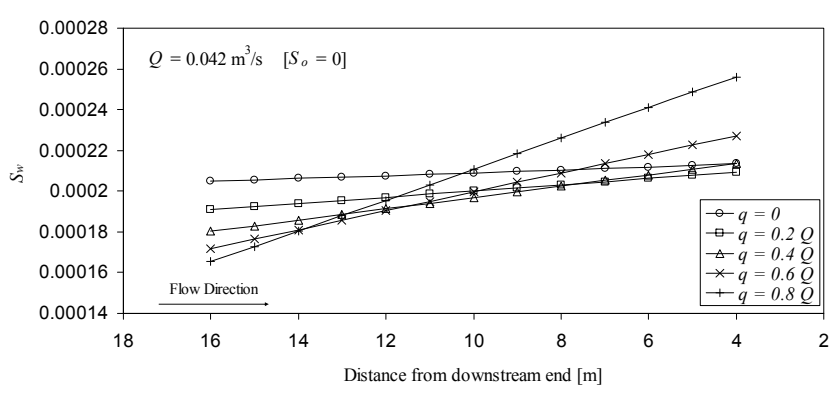

Figure $2 b$

Downstream behaviour of water surface slopes $\left(S_{0}=0\right)$

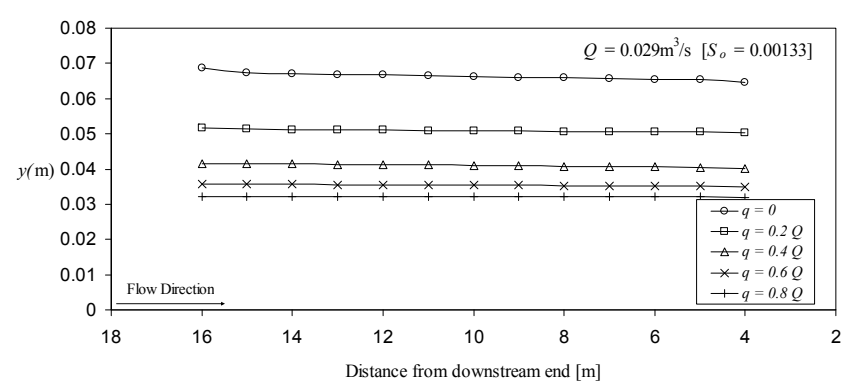

Figure 3a

Flow depth variation in sand bed channel affected by seepage $\left(S_{o}=0.00133\right)$

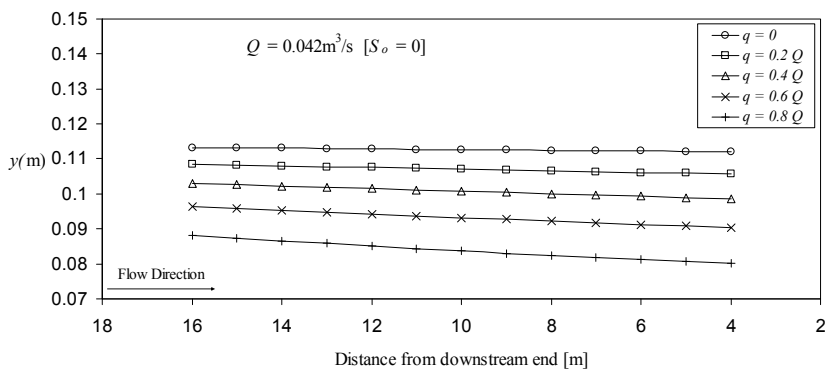

Figure $3 b$

Flow depth variation in sand bed channel affected by seepage $\left(S_{o}=0\right)$

slopes criss-cross the no-seepage water surface slopes. At the upstream end, water surface slopes get reduced because of erosion taking place at that section. and vice versa for the behaviour at the downstream end. The erosion and deposition behaviour should also affect the flow depth, shown in Fig. 3. The effect of bed suction on the velocity distribution was studied numerically by Prinos (1995). Prinos (1995) studied the effects of bed suction on the structure of turbulent open 

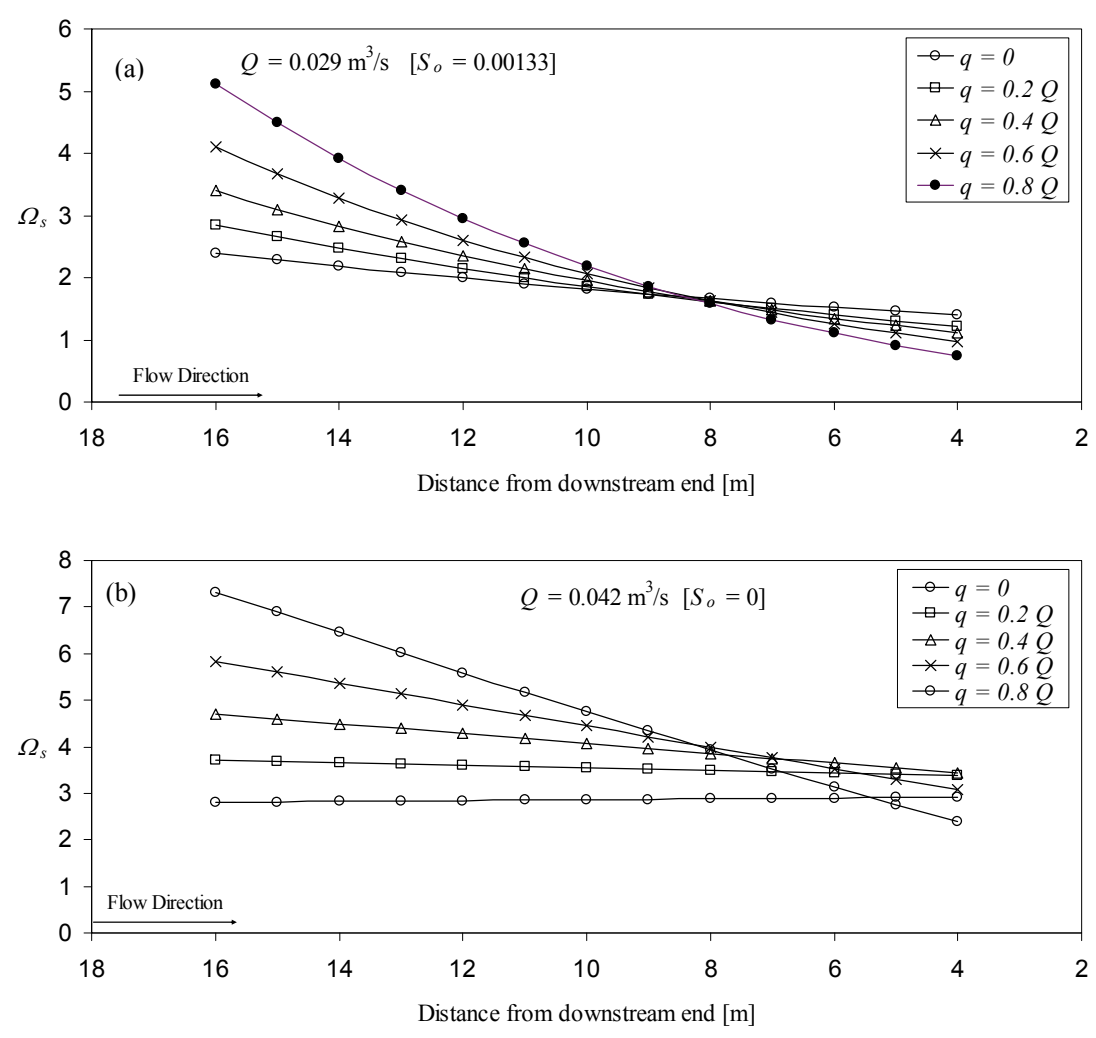

Figure 4a

Stream power

variations over the channel length $\left(S_{0}=\right.$ 0.00133) channel flow by solving the Reynolds averaged Navier-strokes equations. Prinos (1995) found that the suction significantly affects the mean flow characteristics. The near-bed velocities are increased with increasing suction rate, as well as the bed shear stress. The excess bed shear stress resulting from suction is calculated as the order of 3 to 8 times the excess bed shear stress, when compared to the no-seepage value. The turbulence levels are greatly reduced with increasing suction rate. This will result in lower flow depth when suction is taking place in the channel, as shown in Fig. 3. Experimental observations in the form of Eq. (3) along the length of the channel are plotted in Figs. $4 \mathrm{a}$ and $4 \mathrm{~b}$.

It can be seen from Fig. 4 that, in general, stream power varies nonlinearly downstream due to suction, and stream power always decreases towards the downstream side of the channel. This may be due to loss of kinetic energy while travelling through the downstream side; also, stream power has to spend some of its energy in erosion or deposition of the sediment particles. As shown in Fig. 4, stream power is greater at the upstream side when compared to the downstream side; erosion will take place at the upstream side. Eroded particles resulting from the higher stream power at the upstream side have to be deposited somewhere; this happens at the downstream side of the channel because of lower stream power. Here, it can be supposed that the channel is in 2 distinct regimes, erosion zone and deposition zone; however these zones will depend upon prevailing hydrodynamic parameters. The eroded material from the upstream side is deposited at the downstream side and the channel takes longer to clear this sediment because of the reduction in stream power at the downstream end. At the same time the sediment inflow process is continuous from upstream to downstream and hence the bed level rises continuously. Bed levels rise progressively towards the downstream end leading to aggradation, shown in Fig. 5.

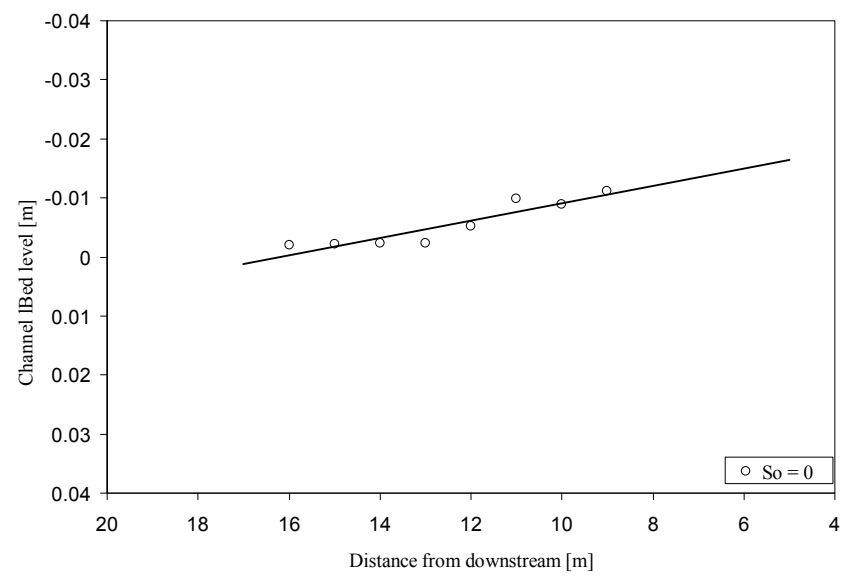

Figure 5

Sectional channel bed levels

Figure 5 shows that erosion and deposition of sand particles takes place at the upstream and downstream ends, respectively.

Given the results presented, frequent failure of reservoirs can be explained. As shown in Figs. 4 and 5, deposition in the downstream side reduces the channel capacity.

\section{Conclusions}

The presence of downward seepage or suction alters the sediment transport characteristics of sand-bed channels; hence, seepage effects should be considered in channel design. Suction decreases the flow depth of the channel. Analyses of experimental observations show that, in the presence of suction, stream power varies non-linearly in the channel. It has been found that stream power decreases in a downstream direction 
due to suction, which indicates that higher stream power prevails on the upstream end. The upstream side of the channel gets eroded due to higher stream power. At the downstream side of the channel, stream power is lower, thus deposition takes place. It can be concluded that deposition taking place at the downstream side will reduce the carrying capacity of the channel.

\section{Acknowledgements}

The authors gratefully acknowledge the financial support that was received from the Department of Science and Technology, Govt. of India (SERC-DST: SR/S3/MERC/005/2010) to carry out the research work presented in this paper.

\section{References}

ABERNETHY B and RUTHERFURD ID (1998) Where along a river's length will vegetation most effectively stabilise stream banks? Geomorph. 23 55-75.

ALI KHM, ACHTERBERG J, LI M and ZHU Y (2003) Effect of seepage on sediment transport in channels. Int. Conf. Estuaries and coasts, 9-11 November 2003, Hangzhou, China. 461-466.

BAGNOLD RA (1963) Mechanics of marine sedimentation. The Sea 3 507-553.

BAGNOLD RA (1966) An approach to the sediment transport problem from general physics. U.S. Geological Survey Professional Paper 422-I 1-37.

BAKER VR and COSTA JE (1987) Flood power. In: Mayer L, Nash D (eds.) Catastrophic Flooding. Allen and Unwin, London. 1-24.

CHENG NS and CHIEW YM (1999) Incipient sediment motion with upward seepage. J. Hydraul. Res. 37 (5) 665-681.

CHOW VT (1959) Open-Channel Hydraulics. McGraw-Hill, New York.

DOBROKLONSKII AV, MIKHAILOVA NA and MULYUKOVA NB (1976) Effect of seepage flow on the rate of detachment of solid particles from the bed. Power Technol. Engin. 11 37-40.

FONSTAD MA (2003) Spatial variation in the power of mountain streams in the Sangre de Cristo Mountains, New Mexico. Geomorph. 55 75-96.

KNIGHTON AD (1987) River channel adjustment - the down stream dimensions. In: Richards KS (ed.) River Channels: Environment and Process. Blackwell, Oxford. 95-128.

KNIGHTON AD (1999) Downstream variation in stream power. Geomorph. 29 293-306.
LAWLER DM (1995) The impact of scale on the processes of channelside sediment supply: a conceptual model. In: Effects of Scale on Interpretation and Management of Sediment and Water Quality. Proc. Boulder Symposium, July 1995. Int. Assoc. Hydrol. Sci. Publ. 226 175-184.

LECCE SA (1997) Nonlinear downstream changes in stream power on Wisconsin's Blue River. Ann. Assoc. Am. Geogr. 87 471-486.

LIMA AG (2007) Cartographic scale effect on channel slopes and stream power calculations. Available from Nature Precedings URL:hhttp://hdl:10101/npre.2007.1359.1.

LU Y, CHIEW YM and CHENG NS (2008) Review of seepage effects on turbulent open-channel flow and sediment entrainment. $J$. Hydraul. Res 46 (4) 476-488.

MACLEAN AG (1991) Bed shear stress and scour over bed-type river intake. J. Hydraul. Eng. ASCE 117 (4) 436-451.

MAGILLIGAN FJ (1992) Thresholds and the spatial variability of flood power during extreme floods. Geomorph. 5 373-390.

MARTIN Y and CHURCH M (2000) Re-examination of Bagnold's empirical bedload formulae. Earth Surf. PROCESSES LANDF. 25 1011-1024.

OLDENZIEL DM and BRINK WE (1974) Influence of suction and blowing entrainment of sand particles. J. Hydraul. Div. ASCE 100 935-939.

PETIT F, GOB F, HOUBRECHTSA G and ASSANI AA (2005) Critical specific stream power in gravel-bed rivers. Geomorph. 69 92-101.

PHILLIPS JD (1989) Fluvial sediment storage in wetlands. Water Resour. Bull. 25 867-873.

PRINOS P (1995) Bed-suction effects on structure of turbulent openchannel flow. J. Hydraul. Eng. ASCE 121 (5) 404-412.

RAO ARK (2005) A digital micro-manometer for very low pressure measurement. J. Instrum. Soc. India 35 (1) 54-64.

RAO ARK and SITARAM N (1999) Stability and mobility of sandbed channels affected by seepage. J. Irrig. Drain. ASCE 125 (6) 370-379.

RAO ARK and SREENIVASULU G (2009) Design of plane sand-bed channels affected by seepage. Periodica Polytechnica-Civil Eng. 53 (2) 81-92.

VANONI VA and BROOKS NH (1957) Laboratory studies of the roughness and suspended load of alluvial streams. Sedimentation Laboratory, California Institute of Technology, Pasadena, California, USA.

WOHL E (2000) Mountain Rivers. American Geophysical Union, Washington, DC. 320 pp.

VELIKANOV MA (1954) Gravitational theory for sediment transport. J. Sci. Sov. Union Geophys. 4

WILLETS BB and DROSSOS ME (1975) Local erosion caused by rapid infiltration. J. Hydraul. Div. ASCE 101 (2) 1477-1488. 
Available on website http://www.wrc.org.za ISSN 0378-4738 (Print) = Water SA Vol. 37 No. 1 January 2011 